\title{
Technology and Application of Overhead Transmission Line Corridor Inspection
}

\author{
Deng Yuanjing \\ China Electrical Power Research Institute \\ 10055,Beijing,China \\ E-mail: dengyuanjing@epri.sgcc.com.cn
}

\author{
Xia Kaiquan \\ China Electrical Power Research Institute \\ 10055,Beijing,China \\ E-mail: xiakq@epri.sgcc.com.cn
}

\author{
Ren Xichun \\ China Electrical Power Research Institute \\ 10055,Beijing,China \\ E-mail: rxc@epri.sgcc.com.cn
}

\author{
Zhang Hao \\ State Grid Zhejiang Electric Ningbo Power Supply \\ Company \\ 315016,Ningbo,China \\ E-mail: zhanghaohust@126.com
}

\begin{abstract}
The efficiency and quality of overhead transmission line corridor inspection make a close connection to the operation of the whole electrical power system. In this paper, we summarized three common modes of line inspection and analyzed their characteristics. The technologies applied in line inspection are studied and the examples are given. Additionally, it is suggested that further research should be conducted in the cooperative line inspection (helicopter, unmanned aerial vehicle and manual work) with LIDAR (Light Detection and Ranging) and overhead line monitoring system to fulfill the digital and visual-reconstruction power transmission grid. Applying big data technologies, such as data warehouse, distributed processing, data mining to save and analyze inspection data is a required trend. On-line monitoring data and detection data give us a method to provide support for transmission line state evaluation and decision-making advice. Thus the technology of corridor inspection and the better data mining will influence the transmission line state inspection and promote the level of transmission line operation management.
\end{abstract}

Keywords-corridor inspection, cooperative inspection and detection, state assessment, state inspection, big data

\section{INTRODUCTION}

The overhead transmission line is a significant part of the fundamental infrastructure of electrical power system. It takes the task of transmitting and delivering the electricity to the society. With the rapid development of power grid construction and the increase of the scale of power system, transmission lines are mostly in the wild and they are often influenced by bad weather, geographical conditions and construction state. And these factors will endanger the safety and reliability of power system operation. Inspection of transmission line can detect anomalies threatening the circuit safety and provide support for removing dangers and the condition based maintenance. At the same time, improving the quality of transmission line inspection can enhance the ability of the power grid against the serious natural disasters, external damages and reduce the reinvestment for power grid repairing and reconstruction after the damages. It will bring long-term economic benefits for power system operation. Among them, the corridor environment is the major content of the inspection. According to "Monthly Analysis Report of Transmission Lines" of 2014 March, short circuit caused by other obstacles and construction touch-lines accounted for $17.1 \%$ of the total trips in transmission lines above $66 \mathrm{kV}$. While, at this stage, the contradiction between the shortage of inspectors and the increasing inspection workload urges us improving inspection mode and integrating new technologies to increase the inspection efficiency, improve the inspection quality of and raise the management level of power transmission lines.

\section{INSPECTION MODE CLASSIFICATION OF CORRIDOR}

According to DL/T741-2010 "overhead transmission lines operation rules" (referred to as the "Rules"), corridor inspection refers to the examination of the corridor and the surrounding environment along the line, including the cross situation, construction operation and so on. In order to discover and master the dynamic changes of line corridor environment, the inspection object of the corridor environment includes structures and buildings, trees and bamboos, construction situation, the mining influencing area, fire, drainage, infrastructure of foundations, roads and bridges, the source of pollution, natural disasters and other contents.

The inspection is divided into periodical inspection and state inspection according to the different way of inspection periods determine. And the periodical inspection includes normal inspection, fault inspection and special inspection.

Periodical inspection refers to the way of inspection which can rectify the inspection period timely when necessary. And inspection period is determined by the operation and maintenance department according to the line equipment and corridor characteristics of each section, combining the inspection experience. State inspection refers to the way of inspection whose period is determined by the operation and maintenance department through the combination of the historical experiences and the state evaluation of lines and can be rectified dynamically. 
According to the adopted methods and technologies, the corridor environment inspection is divided into the following three categories:

(1) Artificial inspection on the ground.

The line inspections, especially the corridor inspection, are mostly conducted on foot or by car. It is the examination at the fixed dangerous point on the corridor environment along the line and mainly by the visual observation of the inspection staff. In the last century, this method is the main inspection mode of transmission line in our country. This traditional inspection method is confined by the quality of personnel, weather conditions and other uncertainties, which cannot fully grasp the real operating situation of the line.

(2) Artificial inspection on the ground combined with live detection and on-line monitoring.

On the basis of the manual detection on the ground, detection methods such as the handheld terminal can be adopted to test the actual situation, obtaining the accurate data in detail, finding the hidden troubles, providing the scientific basis for the implement of the state evaluation. Especially in the special line segments where the traffic is inconvenient, the auxiliary inspection by the on-line monitoring devices can be applied. After the ice disaster in the southern area in 2008, the development put forward the promotion and application of the on-line monitoring system for the transmission lines in nationwide. The online monitoring system of the transmission line can obtain the state information of the line through the sensors and the photographic equipment installed on the line. And the data will be analyzed to determine the abnormal situation of the line and the results will provide a certain ability of fault prediction. Through on-line monitoring we can realize the real-time monitoring of the grid and centralized management. Moreover, in order to reduce the times of the inspector's on-tower examination and improve the efficiency of the line inspection and, many domestic technical experts carried out researches on intelligent robot inspection to provide an assistance for staff, whose patrol path can be set or manipulated, using the carried inspection system to send back the obtained data.

The way of combining the artificial inspection and the live detection has a relatively higher efficiency over the traditional way. The negligible faults when inspecting with our naked eyes can be found the hot point effectively by the infrared ray detection. But what is insufficient is that, the equipment is on the ground and infrared detection quality is not accurate enough, and the faults of part of the hardware, pin, discharging clearance of tower head and insulator are not easy to find.

(3) Helicopters, unmanned aerial vehicles (UAV) and artificial inspection

In order to improve the operation management level of the transmission line, improve the inspection efficiency and reduce labor intensity of inspection personnel, the State Grid Corporation promoted the helicopters, drones and artificial collaborative inspection mode in 2013. For three-dimensional inspection, this type of inspection is applied for $220 \mathrm{kV}$ and above especially for the $500 \mathrm{kV}$ lines. In 2003, North China became the first helicopter inspection. At the same time, the UAV inspection operating mode was launched. Until now, the State Grid General Aviation Company has accumulated the practical experience for the helicopter line inspection in many provinces.

Helicopters and UAVs inspection generally uses the far infrared thermal imaging instrument and the visible light cameras and other advanced equipment. Through the multi-angle overlook and lateral-view detection, the helicopter and the UAV patrols are not restricted by the terrain conditions, hence, we can find some hidden faults which are hard to find in the manual inspection, and the computer data analysis can be carried out through the configured system.

The helicopters, UAVs and artificial collaborative inspection method of current inspection are mainly developed by the company of Hebei, Liaoning, Zhejiang, Hubei and Sichuan provinces. Based on the former study of the effect analysis of the helicopters, UAVs and artificial patrol has higher probability of finding the hidden faults. The helicopters and the UAVs use the infrared imagers with stable gyros onboard, having great advantages in finding concealed defects, and manual patrol using the handheld infrared imagers cannot implement the whole comprehensive detection due to the inspection position limit. In the research of finding the location of the faults, due to the difference in the patrol position and the observation angle, artificial inspection is suitable for the problems of base damage and tower material loss, while, helicopters, UAVs for guide wire and insulator problems. In the plain area, the numbers of these two kinds of faults are almost equal, so the manual patrol should be the major measure and the helicopters and UAVs should be used as an auxiliary method. While in mountainous terrains, the wires, fittings and insulators will have more problems which maybe more serious, and the traffic inconvenience needs to be taken into consideration. The application of the helicopters and UAVs will greatly improve the inspection efficiency. At the same time, carrying out the helicopters, UAVs and artificial collaborative patrol on the UHV transmission lines and other key lines will improve the operation safety and the operation management and the technology level of the transmission lines.

TABLE I. MODE OF INSPECTION

\begin{tabular}{|c|c|c|}
\hline \multirow{2}{*}{ mode } & \multicolumn{2}{|c|}{ Characteristic } \\
\hline & advantages & disadvantages \\
\hline $\begin{array}{l}\text { Ground } \\
\text { artificial } \\
\text { inspection }\end{array}$ & $\begin{array}{l}\text { 1Promoted widely } \\
\text { 2Easy and effective } \\
\text { to detect the lost } \\
\text { materials and the } \\
\text { external damages } \\
\text { 3low expenses }\end{array}$ & $\begin{array}{l}\text { 1Lower inspection } \\
\text { efficiency and larger } \\
\text { demand on staff } \\
\text { 2Consumption of time, } \\
\text { 3Excessive dependence on } \\
\text { the quality of the personnel } \\
\text { and the weather condition. }\end{array}$ \\
\hline $\begin{array}{l}\text { Ground } \\
\text { artificial } \\
\text { inspection } \\
\text { with live } \\
\text { detection } \\
\text { and on-line } \\
\text { monitoring; }\end{array}$ & $\begin{array}{l}\text { 1Providing data } \\
\text { support } \\
\text { 2online monitoring } \\
\text { system can be used } \\
\text { in traffic } \\
\text { inconvenient part } \\
\text { 3able to realize the } \\
\text { realtime monitoring. }\end{array}$ & $\begin{array}{l}\text { 1Lower stability of the } \\
\text { online monitoring devices } \\
\text { 2lower data reliabilit } \\
\text { 3Inconvinience of the } \\
\text { maintenance of the online } \\
\text { monitoring system } \\
\text { 4insufficient inspection } \\
\text { data information and } \\
\text { unsatisfactory accuracy. }\end{array}$ \\
\hline
\end{tabular}




\begin{tabular}{|c|c|c|}
\hline \multirow{2}{*}{ mode } & \multicolumn{2}{|c|}{ Characteristic } \\
\hline & advantages & disadvantages \\
\hline $\begin{array}{l}\text { helicopters, } \\
\text { unmanned } \\
\text { aerial } \\
\text { vehicles } \\
\text { (uavs) and } \\
\text { artificial } \\
\text { inspection }\end{array}$ & $\begin{array}{l}\text { 13D inspectionl,able } \\
\text { to detect the hidden } \\
\text { faults } \\
2 \text { improved patrol } \\
\text { efficiency } \\
\text { 3providing large } \\
\text { amount of accurate } \\
\text { patrol data. }\end{array}$ & $\begin{array}{l}\text { 1High expenses of the } \\
\text { elicopters and the UAVs, } \\
\text { 2Lower attendance rate, } \\
\text { strict training for the } \\
\text { helicopter,hard training } \\
\text { promote,long to } \\
\text { period,strict maintenance } \\
\text { of the equipment, } \\
\text { 3low endurance, weak wind } \\
\text { resistance,has } \\
\text { electromagnetic } \\
\text { interference for the UAVs. }\end{array}$ \\
\hline
\end{tabular}

\section{THE CORRIDOR INSPECTION TECHNOLOGY}

Now handheld portable testing equipment, such as laser rangefinder to measure sag and tree-line distance, infrared detector to find heat on fittings, UV detector to find out the partial discharge of electrical equipment and corona, are widely equipped and used to inspect the corridor situation besides visual inspection by naked eyes and telescope. Line inspection by intelligent robots with visible light cameras, infrared thermal imagers and other detection equipments carries on inspection the according to the set route, machine vision system can be fused with the GPS system, which made the robots have the autonomous obstacle detection, identification and location, and also the function of images and data storage and remote wireless transmission, wireless monitoring and control, analysis of the background checking operation management and diagnosis and other.

Corridor inspection for special terrain or traffic inconvenience, according to the inspection rules can be monitored by on-line monitoring system for auxiliary. The main on-line monitoring devices mainly include microscopic meteorological monitoring devices, video image device and alarm device to complete the environmental information collection. Through the above devices and online monitoring system, including data base with a frequency of every 20 minutes for a wireless system or OPGW back to the equipment status evaluation center, and the expert software of equipment status evaluation center can take advantage of the model and the result of field operation to judge the situation and make early warning in time by the image of conductor ice, bad geology, tree growth situation, the corridor construction and tower material stolen, and inform the inspection staff pay attention and take appropriate measures.

In helicopters, unmanned aerial vehicle (UAV) with manual inspection, the main devices is infrared thermal imager, equipped with a GPS locator, high resolution digital camera and a visible light camera, etc. Those can detect the problems such damage of ground wire strands, wire connector, temperature difference, insulator explosive line defects. Helicopter horizontal distance is a bit higher than the ground, flew above in a certain speed, using infrared imaging devices on the ground and hardware for inspection, at the same time by LIDAR to obtain high accuracy point cloud, the orthogonal projection as $3 \mathrm{D}$ modeling results, the mathematical accuracy and data quality requirements. Through the transmission line in the point cloud data to extract the features of the three dimensional space distance, determine the dangerous distance of each place, and indicate the category of the dangerous points, such as the situation of vegetation, cross, buildings, etc.

A Power Supply Company and a Mapping and Design Institute conducted a research on transmission line threedimensional visualization and risk monitoring in 2011. This project uses the helicopter equipped with 3D laser radar on the inspection of four $500 \mathrm{kV}$ transmission line. Hundreds of potentially dangerous points were found. And the dangerous points were categorized and exact coordinates were provided. Also the related profile such as the longitudinal section images and the orthorectification images were used for accurate measurement for trees and structures distance. Thus will give timely advice for operation and maintenance staffs to arrange targeted inspections and increase the intelligence of transmission lines significantly. In summary, making advantages of different modes of inspection will improve the quality and efficiency of inspection to achieve economic and social improvement.

\section{THE DEVELOPMENT TREND OF CORRIDOR INSPECTION TECHNOLOGY}

By using the Light Detection and Ranging (LIDAR), a measure system which is fast, non-contact, high precision and efficiency, collaborative inspection with helicopters, unmanned aerial vehicles and inspection staffs will express its potential. We can get $3 \mathrm{D}$ data of transmission lines. The digitization and visualization of transmission lines' information can be achieved by all-digital, intelligent data processing, combined with transmission line on-line monitoring system. It includes 3D visualization of digital transmission network, transmission line route corridor reconstruction, spatial distance analysis and automatic feature detection on vegetation, buildings and other dangerous places. And the full range visual power line corridors observation for inspection staff is supported.

By integrate static data of planning and design and dynamic data of inspection and monitoring, the combination of online monitoring data with inspection data by different means, can provide whole process line corridor with no blind area of $3 \mathrm{D}$ data for the realization of the visual grid possible. To establish suitable for multisource data information channel and professional database, a concept of "big data" is introduced to transmission lines management, including data fusion and mining, for condition evaluation of transmission line with solid data to support. Establish a cloud computing platform with transmission line model and expert evaluation system to implement the intelligent of the power grid security warning, prevention and emergency handling, and offering operation strategy recommendations.

Combining on-line monitoring system in inspection, continuing studying in the digitization and visualization of power transmission lines data can help to carry out state evaluation, determine the inspection cycle for dynamic adjustment, deepen explore and develop of transmission line inspection.

But transmission on-line monitoring data value density is low. Because most of the data collected are normal data and only a small amount are abnormal data. While abnormal data is the most important basis for condition based maintenance. And in the condition monitoring 
system of transmission lines, in order to find out the discharge of insulator leakage current there will be high sampling frequency with large amount of data. Theoretical study on the diagnosis method of artificial intelligence in fault was much, but diagnosis by threshold is common used in practical applications. And the results usually are not accurate due to the low accuracy and the inadequate mining. The helicopter patrol line of pictures and videos, at present still rely on human treatment, there is the lack of effective means of intelligent analysis.

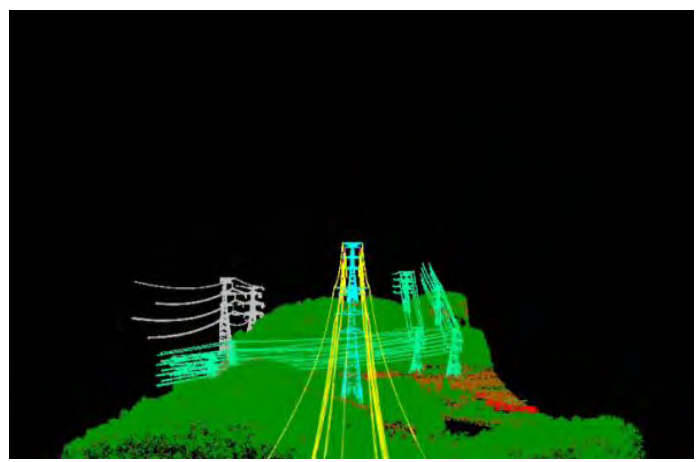

Figure 1. 3D scanning image of transmission linecorridor

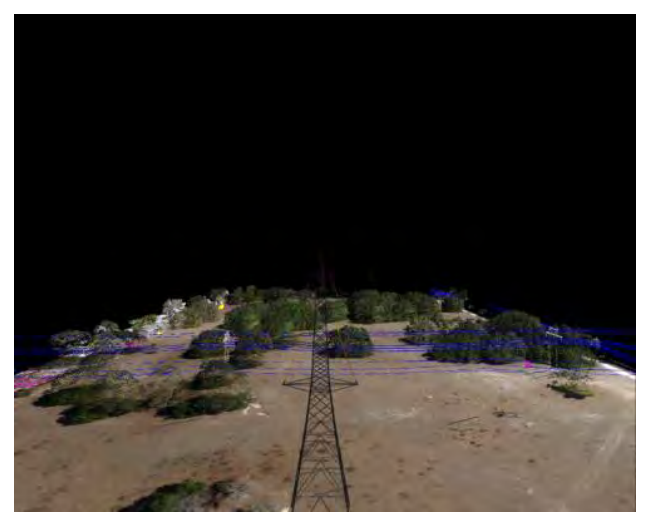

Figure 2. 3D image reconstruction of transmission line corridor

\section{CONCLUSION}

This paper reviews the current technology and characteristics of three modes inspection, i.e. artificial transmission line inspections, inspections assisted with online monitoring and live detection, the inspection collaborated with helicopters, unmanned aerial vehicles and staffs. The paper also states the development trend of corridor inspection technology. And point out that the digitization and visualization of power transmission lines information can be realized by using helicopters, unmanned aerial vehicles and staffs collaborative inspection mode combined with the transmission on-line monitoring system. With cloud computing platform and the big data technologies, such as data fusion and mining, inspection will offer solid support to evaluate transmission lines and make decisions for maintenance, thus advance the efficiency and quality of transmission line inspection, improve the management level of transmission lines operation and maintenance.

\section{REFERENCES}

[1] XIE Zhiwu. Study of Online Monitoring Technology for High Voltage Transmission Lines[J]. Chinese Electrical Education, pp. 180-181, April 2013.

[2] WANG Xianhua and LI Jianyun. The Manufacture of the Inspection Robots for Transmission Lines[J]. Mechanical and Electrical Information, pp.146-148, March 2013.

[3] SHAO Yunlin, CAO Jinen and SHANG Dawei. The Helicopter inspection of the EHV transmission lines in North China[J]. China Electrical Power, pp. 35-38, 2003, 36(7) .

[4] SHU Yinbiao and HU Yi. The Operation and Maintenance and the Live Working for the EHV AC Transmission Lines[J]. High Voltage Engineering,pp.1-5,2008,33(6).

[5] ZHANG Hong.The Research of Condition Based Operation and Maintenance Manageent of Overhead Transmission Line[D].Peking:North China Electric Power University,2012.

[6] YU Deming, SHEN Jian, WANG Jun, et al. The Comparation and Analysis of the Effects for Helicopter and Artificial [J]. China Electrical Power, pp. 25-28, 2008, 41(11).

[7] YI Lei and LU Guiwen. The Application of the Airborne Laser Radar In Circuit Design[J]. The science and technology innovation herald, pp. 65-66, 2013, 17.

[8] QIU Guoxin. Review of High Voltage Transmission Lines Inspection Based On the Infrared Thermal Image Technology Applied to Helicopters[J]. Electrical Power in Guangdong, pp. 7375, 2005, 3(3),

[9] CHENG Guokai and WANG Congmin. Discussion On the Construction of the State Inspection System of Transmission Lines[J]. Electrical Power in Zhejiang, September 2013, pp. 11-13.

[10] Y.J.Deng,J.C.Yu,K.Q.Xia, and L.Liang, Corrision Condition Analysis of In-service ACSR Overhead Lines, Advanced Research in Material Science and Mechanical Engineering, Trans Tech Publications, 2013, pp. doi:10.4028/www.scientific.net/AMM.446-447.753 